\title{
Supervivientes del Apocalipsis: un relato de ciencia ficción 'gitano'
}

\author{
Apocalypse Survivors: A ‘Gypsy’ Sci-Fi Tale
}

María Sierra

Universidad de Sevilla

\section{RESUMEN}

En 1977 Monde Gitan, una revista francesa dedicada a la llamada "cuestión gitana”, publicó un artículo titulado Les survivants de l'Apocalypse, de Jean Ortica, integrante de una conocida familia 'gitana' del país. Se trata de un breve relato de ciencia ficción centrado en una catástrofe nuclear. En la historia, una familia de supervivientes debe aprender a vivir desde cero, sin poder apoyarse en la herencia de siglos de civilización. Son los romaníes quienes se sienten, en consecuencia, protagonistas de la historia de la humanidad y responsables del nacimiento de un nuevo mundo.

Este relato puede ser leído de varias maneras, desde una historia de ciencia ficción distópica hasta una utopía gitana; incluso, podría ser entendido como un intento de adoctrinamiento asimilacionista por parte de la sociedad mayoritaria, desde una visión "civilizatoria". El artículo explora estos múltiples sentidos como vía de entrada para el estudio de la situación del pueblo romaní en la Francia (y la Europa) de posguerra, teniendo en cuenta los factores sociales y culturales del contexto histórico -señaladamente, el miedo atómico propio de la Guerra Fría- pero también la situación del pueblo romaní tras el Holocausto nazi. Se trata de una forma de representar y combatir el anti-gitanismo desde la imaginación de la capacidad de agencia en un contexto de ficción extremo.

PALABRAS CLAVE: Literatura romaní, "cuestión gitana”, utopía, distopía, Holocausto 


\section{ABSTRACT}

In 1977 Monde Gitan, a French journal devoted to the so-called "Gypsy Question" published an article entitled "Les survivants de l'Apocalypse". Its author was Jean Ortica, a member of a well-known "gypsy" family in France. It was a Science Fiction short story portraying a nuclear disaster. The narration stresses on how a surviving Roma family have to adapt and live starting from scratch, incapable of relying on the inherited history of centuries of civilization. The Roma are the people who thus play the main role in the new history of the humankind, feeling responsible for the birth of a new world.

This story can be read in several ways, from a dystopian science fiction story to a gypsy utopia narration; It could even be understood as an attempt at assimilationist indoctrination by the majority society, from a "civilizatory" vision. The article explores these multiple meanings in connection with the study of the situation of the Roma people in post-war France (and Europe), taking into account the social and cultural factors of the historical context remarkably, the rise of nuclear fear in the Cold War- but also the situation of the Roma people after the Nazi Holocaust. This story represents and faces antigypsyism from the self-imagination of the Roma capacity for agency within a fictionalized extreme context.

KEY WORDS: Romani Literature, “Gypsy Question”, Utopy, Distopy, Holocaust

2 de mayo de 1985: La guerra atómica estalla alcanzando desde Estados Unidos a Rusia, desde China a Francia; después de diez días, el mundo está prácticamente destruido y la gente muere por miles como consecuencia de las radiaciones atómicas. Pero una cosa llamativa sucede: los gitanos se dan cuenta de que ninguno de ellos se ve afectado. ${ }^{1}$ Así empieza un breve relato, que podría ser

\footnotetext{
${ }^{1}$ El término gitano se usa en este texto en tanto que categoría empleada por las fuentes y el discurso que se somete a análisis (y como tal aparece entrecomillado solo la primera vez); precisamente en el contexto histórico en el que se sitúa el caso de estudio aquí abordado se produjo el surgimiento del término romaní como autodenominación con intención política. Este trabajo se inscribe dentro de los proyectos de investigación HAR2015-64744-P y BESTROM "Beyond Stereotypes: Cultural Exchanges and the Romani Contribution to European Public Spaces",
} 
calificado como ciencia ficción distópica, publicado en 1977 en una revista titulada Monde Gitan. ${ }^{2} \mathrm{Si}$ el lector avanza un par de párrafos, encuentra la explicación, puesta en boca de un profesor de medicina que habla por la radio:

El mundo entero debe morir como consecuencia de las radiaciones atómicas, salvo las Gens de Voyage que son de sangre gitana. Solo estas personas podrán sobrevivir y volver a comenzar un mundo nuevo" ("Le monde entier doit mourir par les radiations atomiques, sauf les Gens du Voyage qui ont du sang gitan. Il n'y a que ces gens qui pourront survivre et recommencer un nouveau monde, p.14).

Gens de Voyage -literalmente "personas de viaje"- remite a una categoría administrativa francesa relativamente ambigua aplicada a las familias que, sin domicilio fijo, viven del ejercicio de profesiones itinerantes o en ocasiones no tienen un oficio definido. En combinación con la obligación de portar un carnet antropométrico especial, instituida a partir de una ley de 1912, esta categoría ha operado como etiqueta estigmatizadora, especialmente por la identificación dominante entre el nomadismo y la población romaní. ${ }^{3}$ Esta tradición de criminalización preventiva, con efectos policiales y judiciales, que no es por otra parte exclusivamente francesa, está estrechamente relacionada con la persecución a la que fue sometido el pueblo romaní en toda la Europa controlada por el nazismo durante la Segunda Guerra Mundial (Foggs 2013; About 2012).

Pues bien, si tenemos en cuenta que el autor de este relato es miembro de un pueblo que puede ser justamente considerado la víctima olvidada del Holocausto nazi (Zimmermann 2001), el hecho de convertir en protagonistas de su historia a los gitanos -como únicos supervivientes posibles de una hecatombe- llama en sí mismo poderosamente la atención: este punto de partida para un relato de

financiado por HERA Joint Research Programme (www.heranet.info) cofinanciado por AoF, NCN, AHRC, AEI and the European Commission a través de Horizon 2020. ${ }^{2}$ Les survivants de l'Apocalypse, par Jean Ortica, Monde Gitan (Paris), № 41, 1977, pp. 13-21.

${ }^{3}$ La identificación no es exacta: según una nota del Ministerio del Interior en 1967 vivían en el país unos 80.000 tzigane (otra denominación de la época). La mayoría pero no todos los 100.000 "forains" y 10.000 "nómades" (dos subcategorías administrativas) serían de origen gitano. En todo caso, la abrumadora mayoría eran ciudadanos franceses. "Nota relativa a los problemas concernientes a las poblaciones nómadas o de origen nómada, febrero 1967 (Archives Nationales, Francia)". 
ciencia ficción encierra toda la potencia proyectiva de una narración que se atreve a invertir imaginariamente un genocidio histórico. Es en este marco en el que se inscribe el análisis que se ofrece a continuación sobre este peculiar texto y su contexto.

\section{UNA HISTORIA IMAGINARIA DE SUPERVIVENCIA}

La historia que nos sirve de hilo de Ariadna es un relato breve, de nueve páginas, titulado Les survivants de l'Apocalypse (Los supervivientes del Apocalipsis) y firmado por Jean Ortica. La revista que lo publica en su número 41 (1977), Monde Gitan, le añade una introducción en la que el narrador es presentado como un "Gitan", miembro de una familia honorable, numerosa y bien conocida dentro del mundo del "Voyage". Dos datos se solapan en esta presentación para destacar la originalidad del narrador: primero, que su grupo familiar sea conocido entre sus pares con el apelativo de los "silenciosos", por su tendencia a hablar poco; segundo, que el autor se lance con un relato lleno de imaginación sobre el porvenir, cuando supuestamente los gitanos no serían muy dados a pensar sobre el tiempo futuro (ni sobre su pasado). Volveremos luego sobre esta última cuestión.

Interesa antes resumir brevemente el relato, que nos lleva en zigzag por las aventuras y desventuras del clan Ortica, en una serie de episodios separados por saltos temporales desiguales. En el primero de ellos estalla la catástrofe nuclear, el mundo queda devastado y lo miembros de las familias gitanas van buscándose para afrontar juntos el reto de la supervivencia. Transcurre un duro invierno: "Todo esta desolado, sin vida, sin luz" ("Tout est désolé, sans vie, sans lumière)". Viven de las provisiones que encuentran, pero les pesa la soledad y les preocupa qué traerá el futuro. Los más viejos reflexionan, buscan ideas, “Qué haremos?", se preguntan (p. 14). El relato ha empezado en modo claramente distópico, de forma bastante homologable a otras historias de ciencia ficción ambientadas en catástrofes nucleares tan frecuentes en aquel momento.

Pasado un año, la comunidad ha decidido instalarse en una villa que ha quedado vacíada de sus anteriores habitantes y cultivar la tierra para obtener alimentos. Puesto que encuentran simientes, herramientas y tractores, se ponen manos a la obra y lo consiguen. Cuando llega la cosecha, están contentos por haber logrado algo que hasta entonces "les parecía imposible" ("una chose que nous semblait imposible autefrois”, p.15). [Imagen 1: recogiendo la cosecha] 


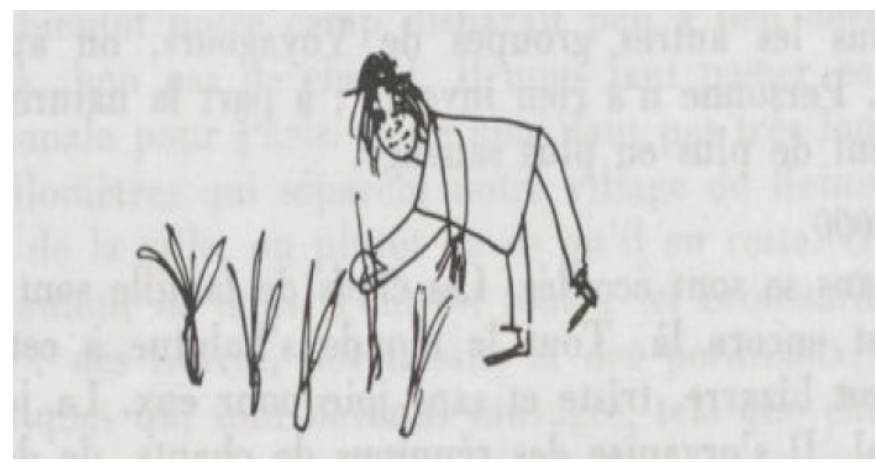

Pero no solo de pan vive el hombre: con alegría se enteran de que otra familia de gente de viaje vive en una comarca cercana y les visitan para acordar intercambios; ellos pueden proveerles del vino y champán que han aprendido a hacer, mientras que la otra familia les puede proporcionar plantas para que cultiven patatas y otras verduras. "Todos estamos muy contentos", dice el narrador ("nous sommes tous très contents de cette rencontre qui nous a beaucoup appris", p. 15).

Pero la dicha dura poco. El siguiente episodio se sitúa en junio de 1990, cinco años tras el estallido de la guerra. Para entonces, se hace evidente el agotamiento de los recursos heredados que hasta ahora les había permitido soñar con el progreso: las herramientas se van estropeando, no queda gasolina y no pueden usar motores para sus trabajos. [Imagen 2: sin gasolina]

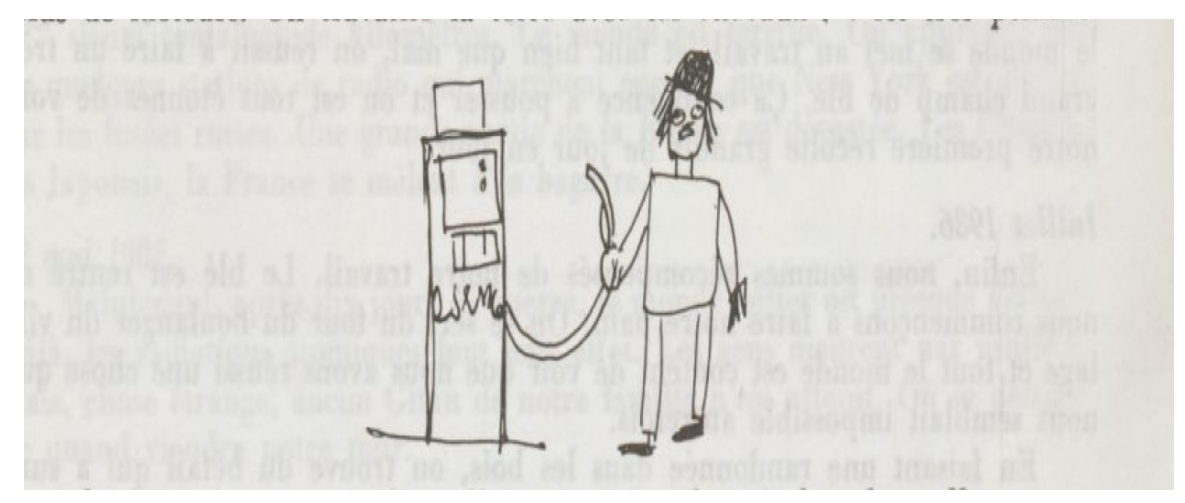


Diez años después de la guerra, en junio de 1995, la situación es ya claramente distópica: las nuevas generaciones se van acostumbrando a vestir con pieles; no hay médicos ni medicinas; no hay inventos que lleven a los humanos más allá del estado de naturaleza y supervivencia; van siendo engullidos por el bosque y todo se confunde con la naturaleza; se pierde el sentido del tiempo... "No queda prácticamente nada de la civilización que conocimos" ("il n'y a pratiquement plus

rien de la civilisation que nous avons connue", p. 16). La única ventaja es, que gracias a la inexistencia de polución, la fauna y flora son riquísimas y no les faltan en consecuencia recursos alimenticios.

En este plano inclinado decadente, compartido con otras familias gitanas, se mantienen hasta que un buen día, en el año 2000, se animan a correr una aventura, a explorar una idea. Se les ha ocurrido organizar un viaje a Paris, a 300 kms. de distancia, para ver qué encuentran que pueda ayudar a la supervivencia de la comunidad. Todos preparan con cuidado la excursión arriesgada, que ha de durar al menos veinte días, dotando de provisiones a los tres carros que parten hacia la capital. Cuando llegan, se encuentran una escena triste; de hecho, apenas reconocen la ciudad, destruidas manzanas enteras de casas y tomada por la vegetación. Sin embargo, comparten con otros gitanos la suerte de encontrar en unos grandes almacenes provisiones en buen estado que serán un regalo para la comunidad: telas, máquinas de coser, botes de perfume, navajas, jabón, coñac, whisky... "y toda clase de cosas que son útiles para la familia" ("et des toutes sorte de choses qui sont trés útiles pour la famille", p.19). Lo cargan todo en los carros y de vuelta a casa lo celebran con una fiesta como merece la ocasión, una "très belle soire" en torno al fuego (p. 20). [Imagen 3: carros]

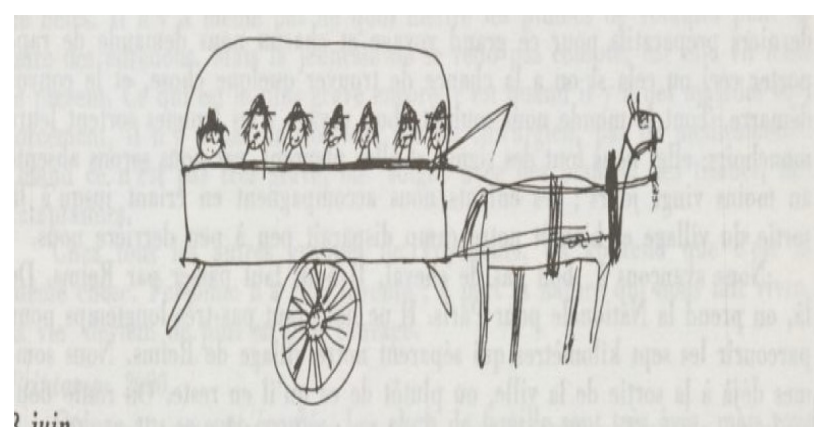


El siguiente episodio se sitúa sesenta años después de esa fiesta. En el año 2060 se sabe ya que el cargamento mágico traído con tanta ilusión desde París había sido un espejismo breve; gastado hace tiempo, ya solo se puede vivir en un estado de salvajismo prehistórico. Los hombres lucen largas cabelleras y barbas, todos se cubren con pieles porque no quedan ya vestidos; no hay herramientas de metal, solo pueden hacerlas de madera... "Nada queda de la civilización" ("Il n'y a plus rien de civilisé; c'est l'état sauvage complet", p. 20). Lo único que se desarrolla es el bosque selvático, lleno de leones, boas y otros animales salvajes; la vegetación incluso desdibuja los caminos que podían unir a la pequeña comunidad con otras similares. Se preguntan si en otras familias de gitanos sucederá lo mismo.

Cuando la naturaleza está a punto de engullirlos, la historia da un último y definitivo giro. Un día, los hombres se reúnen en asamblea para tratar de la situación. Tras el acostumbrado turno de palabra y gracias a la opinión de algunos saben leer y escribir, dan con la clave salvífica: la educación. Hay que crear una escuela, donde los niños se formen y donde también pueda acudir todo aquel que desee instruirse, porque es con el cultivo de las capacidades intelectuales humanas con lo que se podrá salir del estado de naturaleza:

Esperamos que en unos pocos años, algunos tengan el grado de inteligencia necesario para los trabajos y los inventos, y así mejorar nuestra forma de vida" ("on espère que d'ici quelques années, certains auront peut-être un certain degré d'intelligence pour faire des trouvailles, des inventions et ainsi améliorer notre façon de vivre, p. 21).

A modo de colofón abierto, el narrador introduce un último episodio-epílogo, situando en el año 2070. Solo diez años después de la decisión de fundar una escuela, la comunidad es otra: todo está en orden, las calles y las casas; florecen todo tipo de trabajos y talleres, y cada uno se especializa en lo que prefiere; y, sobre todo, el futuro se promete feliz, gracias al rápido desarrollo de las capacidades intelectuales de las nuevas generaciones.

Esperamos hacer grandes progresos pronto... El futuro nos lo dirá" ("On espère bientôt faire de grands progres....'avenir nous le dira, p. 21).

\section{¿UTOPÍA GITANA O ADOCTRINAMIENTO BLANCO?}

Tras este relato en zigzag por las aventuras y desventuras del clan Ortica, ora distópico ora esperanzador, hay una gran pregunta y varias posibles respuestas. La pregunta de fondo viene planteada por el dilema de qué son capaces de hacer 
los gitanos en una situación extrema como la del fin de la sociedad conocida y la consecuente necesidad de soportar sobre sus hombros la construcción de un mundo nuevo. En este sentido, en el relato aparecen cuestiones relevantes como son el valor de la tecnología y la función social de los conocimientos heredados, o el reto inverso de empezar desde cero, de ser protagonistas de la construcción ex novo de la vida social. Son cuestiones que, obviamente, deben ser abordadas críticamente, relacionando el texto con sus contextos. Para ello, resulta clave indagar en las voces que hablan en este relato: ¿quién se expresa realmente a través de él? ¿Para qué clase de discurso e intención resulta esta historia de ciencia ficción un lugar de enunciación? Varios planteamientos son posibles llegados a este punto, y no resultan en absoluto excluyentes.

Una primera lectura interpretativa puede entender el relato como una utopía gitana -utopía no en el sentido de ilusión impracticable sino como impulso político y estético dirigido a cambiar el mundo, según se propone en Mannheim (2002) y Levitas (2010)-. Hay en este texto elementos que pueden ser abordados como expresión de una voz que habla desde dentro de esta comunidad. El autor es reconocido, desde dentro y desde fuera de la misma, como miembro del grupo de los gitanos/romaníes franceses, mayoritariamente manouches. Se le identifica además como miembro de la comunidad de "viajeros", que son los protagonistas de hecho del relato: gitanos franceses no sedentarios.

En este mismo registro, yo añadiría un dato de identificación colectiva más, que me hace sostener que el autor piensa desde dentro de su comunidad el marco general del relato. Hay, sin duda, una coordenada transversal, compartida con el resto de la sociedad, que es la del miedo nuclear. Se trata de un componente básico de las inquietudes y movilizaciones de los años 60 y 70, que late en numerosos productos culturales de esta época. Pero hay una segunda coordenada posbélica en este relato que es singularmente étnica, particularmente romaní. Creo que esa supervivencia colectiva imaginada solamente para los gitanos refleja el hecho de que -precisamente- en la década de 1970 se está empezando a desvelar el genocidio de este pueblo bajo el nazismo. A pesar de la enorme resistencia del gobierno alemán a reconocer que los romaníes fueron objeto de persecución bajo el nazismo por motivos raciales (Margalit 2013; Milton 1998), se están produciendo las primeras reclamaciones y los primeros estudios de forma sostenida (Kenrick y Puxon 1972). Es algo que abre un nuevo horizonte de posibilidades, permitiendo imaginar un futuro que reta al pasado histórico; y es algo que se hace desde una identidad colectiva de definición étnica que empieza a estar enmarcada en la memoria del Holocausto (Kapralski 2013). 
Un tercer argumento para avalar la interpretación de una genuina autoría gitana es la de que el autor introduce en el nuevo mundo que está creando con su relato elementos que son propios de la cultura de esta comunidad, incorporando valores reconocibles desde dentro de la misma. Hay varios datos significativos en este sentido. Así, por ejemplo, el valor otorgado a la reunión familiar y grupal especialmente en la fiesta de celebración del reencuentro tras la expedición parisina, pero también en otros muchos momentos-; o la importancia de recuperar la alegría de vivir que se expresa de forma intensa en esas mismas celebraciones. Hay también lugar para elementos más estructurales de la forma tradicional manouche y gitana de organizar la vida social: la relevancia organizativa que tiene la opinión de los mayores, la asamblea con el turno de palabra de todos los hombres para decidir cuestiones relativas a la comunidad... (Liegeois 2009).

Dicho esto, también es cierto que puede sostenerse otra lectura bien distinta para esta peculiar distopía con final feliz, la de ser quizá una narración de intención civilizatoria y procedimientos cooptadores, dirigida hacia los gitanos pero nacida de la sociedad mayoritaria que los considera sujetos inferiores o cuando menos necesitados de tutela. Hay bastantes elementos donde apoyar esta interpretación. En primer lugar, hay que tener en cuenta la mediación que ha podido imponerse sobre la voz del narrador identificado como Jean Ortica. En este sentido, es importante destacar que el relato está publicado en una revista, Monde Gitan, vinculada al entorno católico y eclesial francés, y más, concretamente, a una asociación preocupada por el llamado "problema gitano" (Notre-Dame des Gitans). Hay mucho paternalismo y afán patronizador en sus páginas, que no dejan el estereotipo al margen, como puede verse en la misma portada del número 41. De hecho, el autor y el relato aparecen presentados por una introducción firmada con las siglas A.B., que en sumario se aclara corresponden al abad André Barthelemy. Fue una de las voces fuertes en el considerado "problema gitano" por las autoridades de la época, ocupando el cargo de Aumônier National des Gitans et des Tziganes. No dejó de expresar su opinión como especialista en la forma de vida gitana en aquellas ocasiones en las que el programa paternalista y patrocinador que él representaba se vio confrontado con otras posturas más abiertamente políticas surgidas en el seno de la comunidad romaní (Sierra 2019). Es precisamente desde este pódium de erudito gitanólogo desde el que Barthelemy afirmaba en la presentación con la que introducía a Jean Ortica que los gitanos no tenían por costumbre reflexionar sobre el pasado o el futuro, un lugar común recurrente antes entre los estudiosos, que inferiorizaban así al colectivo romaní en relación a otros pueblos privándole del derecho a la 
Historia (Sierra 2018). Fue, además, un activo sostenedor en la década de 1960 de la política oficial de la República francesa hacia la comunidad gitana.

Este es, justamente, el segundo elemento de peso para interpretar el relato a la sombra de la influencia de un mediador no-gitano: la política en relación a las comunidades nómadas y de origen gitano de la Francia de De Gaulle. Pasada una primera etapa tras la guerra en la que las autoridades francesas ignoraron a las víctimas romaníes del nazismo hasta el extremo de mantener campos de reclusión abiertos (Heddebaut 2018), en la década de 1960 se gestó un cambio hacia una actitud que se presentó como más humana en el trato legal y policial del "problema" (Klímová-Alexander 2006; Liegeois 1976). Las instrucciones gubernamentales propugnaron una política de integración asimilacionista, que aspiraba a incorporar a los grupos gitanos a la forma de vida sedentaria y los modos de productivos propios de la sociedad mayoritaria. ${ }^{4}$ La política venía inspirada por una Comisión Interministerial especial para el estudio de las poblaciones nómadas, con representantes de ministerios de Asuntos Sociales, Interior, Industria, Asuntos Económicos y Finanzas, Educación y Justicia; y estaba presidida por el consejero de estado Pierre Joint Lambert. Esta política fomentó la cooptación de los portavoces romaníes que participaran de ese proyecto integracionista (con instrumentos tan poderosos como la asociación Etudes Tziganes) tanto como persiguió a los potenciales líderes que pretendieron organizar un movimiento autónomo de reivindicación de derechos.

En este marco de colaboración político-eclesial cobra mayor sentido la introducción frecuente en el relato analizado de referentes modélicos propios de la modernidad occidental: la apelación al sedentarismo, la agricultura y el comercio, al orden urbano versus la jungla de la naturaleza..., todo ello remite a una cosmovisión liberal burguesa de largas raíces normativas. Los éxitos de los protagonistas tienen lugar cuando se aproximan al modelo de vida propio de la sociedad mayoritaria, abandonando el nomadismo para asentarse y hacerse agricultores a la vez que procurando imitar y reproducir el mito ilustrado del progreso.

\footnotetext{
${ }^{4}$ La documentación del Ministerio de Interior francés evidencia la intención de "liberalizar" el trato, tradicionalmente hostil, hacia nómadas y gitanos, y el paralelo mantenimiento de prejuicios -como la "indolencia natural" de los gitanos que menciona una Nota sobre la actitud del servicio de policía ante las poblaciones de origen nómada, del Ministro del Interior, 16-3-1964, ANF.
} 
"Los supervivientes del Apocalipsis" podría por tanto ser también leída como una utopía paya de civilización del "otro" gitano. Así lo enunciaba el mismo padre Barthelemy en la introducción que escribió para el relato:

Pero es un futuro en el que los gitanos se han convertido en payos, porque es posible que los payos tengan la clave del destino (Mais c'est un avenir où les Gitans sont devenus des Gadjé, car c'est peut-être tout de même le Gadjó qui détient les clés du destin, p.13).

Más allá de la lectura interesada y voluntarista que el eclesiástico imponía sobre el relato, es obvio que en el autor del mismo habían influido ideas sobre el progreso, la civilización y la felicidad social que formaban parte de la cosmovisión liberal-conservadora propia de la cultura política mayoritaria. Sin embargo, la forma de recibir, resignificar y vivir estas nociones no tiene por qué ser mimética. Por ello, para terminar, este trabajo quiere abrir un último ángulo de visión que me permite sostener que el relato analizado es, sobre todo, una utopía propiamente romaní, y una utopía romaní que proyecta el nuevo mundo imaginable sobre valores concebidos desde un marco cultural resistente y alternativo al modelo de modernidad dominante en el mundo occidental.

\section{UN MUNDO NUEVO ROMANÍ}

Para sostener esta última idea, voy a servirme de la comparación con otro relato gitano más clásico, bien conocido por los estudiosos del área: La Bible des Roms. La tradition Tsigane dévoilée par Zanko. ${ }^{5}$ Se trata de un libro publicado por primera vez en 1959 y revisado con cuidado para la edición de 2017, en el que se recogen muchas horas de conversación entre Zanko, el jefe de una amplia familia kalderash largamente asentada en Francia, y su amigo el padre Chatard, éste último opuesto a la política asimilacionista antes mencionada (Liégeois 2017; Gaussen 2017). En él se combinan relatos míticos sobre los orígenes y las tradiciones del pueblo romaní con abundantes referencias a los problemas que estas comunidades enfrentaban en aquel presente.

${ }^{5}$ La Bible des Roms. La tradition Tsigane dévoilée par Zanko et recueillie par le Révérend Père Chatard, Marsella, Editions Gaussen - Association Tchatchipen, 2017 (edición original de 1959). 
Desde el principio, el relato está atravesado por una pregunta que Zanko recuerda hizo cuando tenía catorce años a su abuelo:

¿Cómo es posible que siempre y sin fin nos persigan en todos lados? ¿Cómo es posible que seamos el único pueblo sin escritura, sin organización, sin un territorio propio, sin ejército ni policía, sin gobierno, sin riqueza ("Comment se fait-il que nous soyons toujours et sans fin chassés de partout? Comment se faitil que nou soyons le seul peuple qui n'ait pas d'écriture, pas d'organisation, pas une terre à lui, pas d'armée ni de pólice, pas de gouvernement, pas de puissance?", p. 29)

Setenta años después, Zanko mantiene la respuesta que su abuelo le dio entonces a él y a otros jóvenes que preguntaban lo mismo: la explicación de todo es que ellos, los llamados gitanos, son descendientes de una "raza de fugitivos". Sobre ellos pesa una maldición que no pueden romper por sí mismos ("une malédiction sur nous ... Nous ne pouvons pas en sortir nous-mêmes, p.51). Necesitan la ayuda de los no gitanos:

Si los jefes de vuestros países nos tienden la mano en vez de lanzarnos a la policía, si a quienes vivimos entre ellos nos instalan en tierras disponibles, si nos dan cuadros para administrarnos, para instruirnos, para hacernos buenos ciudadanos, enseñar a nuestro niños en los oficios y tareas de la economía sedentaria..., entonces verán que pueblo más pacífico, industrioso y fraternal somos ("Si les chefs de vos pays veulent nous tendre la main au lieu de lancer après nous les gendarmes, s'ils installent sur une de leur terres disponibles ceux d'entre nus qui sont chez eux, et s'il nous y donnent des cadres pour nous administrer, nous instruire, faire de nous bons citoyens, prèparer nos enfants aux métieres et à l'économie sédentaires..., ils verronts alors quel peuple pacifique, industrieux et fraternal nous sommes", p.51).

Según el relato de Zanco, si los jefes de las sociedades de acogida se portasen de esta manera generosa, ellos no discutirían sus órdenes: "les seguiremos con los ojos cerrados, felices y confiados, porque somos como niños" ("nous les suivrons les yeux fermés, heureux et confiants, car nous sommes restés des enfants", p.52).

Aquí es donde la comparación con el relato de Ortica muestra la gran diferecia de este último, que contiene un impulso utópico propugnador de cambios en el sentido filosófico y político antes mencionado. La historia de "Los supervivientes del Apocalipsis" parte de similares preguntas a de las del jefe Zanko, pero da distintas respuestas. De hecho, podríamos decir que rompe el "maleficio" de 
origen de aquél con su atrevimiento proyectivo. Es cierto que lo que activa el argumento en la historia de ciencia ficción que estamos analizando es la misma duda sobre la (in)capacidad, la falta de autonomía, la minoría de edad en suma del pueblo gitano. Esta asunción de una subalternidad construida durante siglos por las sociedades mayoritarias es complemente lógica si tenemos en cuenta la enorme potencia de interpelación que tienen los discursos artísticos, científicos, legales, pedagógicos, políticos... tejidos en torno al pueblo romaní a lo largo de los siglos (Charnon-Deutsch 2014). Según el académico romaní Ian Hancock, es muy posible que no haya manera de deshacer la masa de imágenes estereotípicas sobre los gitanos hondamente interiorizadas por las sociedades occidentales a través de innumerables productos culturales. ${ }^{6}$ Reflexionemos, solo como ejemplo, sobre el hecho de que el mismo Zanko, que había nacido en Rusia en 1888, viviese antes de la Primera Guerra Mundial en el Jardin d'Acclimatation que funcionó en París a modo de zoológico humano y que, más tarde, durante la Segunda Guerra Mundial, estuviese internado con su familia en el campo de Lannemezan (Hautes-Pyrénées), de donde no se dejó salir a los allí recluidos hasta 1946, aunque Francia hubiera sido ya liberada de la ocupación nazi (Gaussen 2017).

Pero Ortica pertenece a otra generación. Es una generación que asiste, no sin muchas dudas e incluso conflictos, al fenómeno del surgimiento de asociaciones y movimientos autónomos romaníes. En Francia, además, se desarrolló una iniciativa, la de la Communauté Mondiale Gitane, especialmente beligerante en la creación de una identidad colectiva romaní de base étnico-cultural y en la reclamación de una personalidad política (Sierra, 2019). Se trata de un fenómeno que estaba cuajando a la par en otros muchos sitios, como la misma Alemania, a través de Consejo Central Sinti (Weiss 2013), o en el Reino Unido, por medio del Gypsy Council (Acton 1974; Acton 1971). Este asociacionismo estaba rompiendo el silencio hasta entonces imperante sobre el genocidio romaní ejecutado por el nazismo y por los regímenes cómplices; y, en un paso más allá, estaba relacionando la causa de estas víctimas con la causa más general de los derechos humanos y cívicos que debían reconocerse al pueblo romaní en todo el mundo. Se trata de un movimiento internacional que encuentró culminación en el Primer Congreso Internacional Romaní celebrado en Londres en 1971, del que surgirá la International Romani Union (Acton \& Klimova 2001; Puxon 2000).

\footnotetext{
${ }^{6}$ Ian Hancock, "What's in a name", (accedido 9-9-2018), https://www.utexas.edu/features/archive/2003/romani.html
} 
Desde unas coordenadas generacionales distintas a Zanko, el autor de "Los supervivientes del Apocalipsis" sí se atreve a imaginar salidas para la trampa de la incapacidad asignada, una trampa muy cerrada. Desde dentro de ella hablaba Zanco cuando hilaba leyendas sobre el origen de su pueblo con la aseveración de que "nosotros somos incapaces de decidir, ponernos de acuerdo... de organizarnos" ("nous sommes incapables de nous décider, de nous mettre d'accord, de nous groupez, de nous unir, de nous organiser", p.52). En el relato de Ortica, los gitanos se organizan, deciden, triunfan por sí solos, en un mundo difícil y sin apoyos externos. Algo importante ha cambiado, reflejando no solo las opciones y circunstancias biográficas de un individuo, el autor del relato, sino también el nuevo marco de posibilidades que se está abriendo para toda una generación, una generación que empieza a enfrentarse a la tradicional estigmatización desde planteamientos asociativos etno-políticos retadores. Son planteamientos que en parte habían empezado a desarrollarse ya en el periodo de entreguerras, de forma especialmente prometedora en algunos países de Europa central y oriental, donde surgieron formas modernas de asociacionismo crecientemente autónomo; pero ese tejido fue destruido por el nazismo y no empezó a recuperarse hasta los años 1960 (Klímová-Alexander 2006; KlímováAlexander 2005).

Para concluir, creo que se puede afirmar que -en este marco sociohistórico- el texto en el que se centra este trabajo tiene el valor de permitirnos asomarnos a un discurso propiamente romaní con potencialidad política que está en esos momentos en proceso de articulación. La distopía del Apocalipsis es una utopía gitana, y lo es en varios sentidos. Primero, porque dibuja un horizonte de expectativas nuevo para la comunidad que ha sido históricamente denominada "gitana" y, precisamente en la década de 1970, empieza a reclamar ser reconocida como "romaní. Se trata de un horizonte nuevo, inédito, en tanto que rompe los límites del lugar asignado a los gitanos en la cultura de la modernidad occidental y les convierte en protagonistas activos de un itinerario de progreso. En segundo lugar porque, aún acercándose al metarelato de la civilización, este nuevo mundo gitano incorpora referentes culturales resistentes, propios del modo de vida romaní: el valor de familia, la comunidad, la opinión de los mayores, la fiesta, la alegría del momento presente... Y, finalmente, es una utopía propia antes que un proyecto resultado del adoctrinamiento porque en un breve pero denso párrafo final se diseña un mundo perfecto alternativo que en absoluto resulta inocente políticamente. Merece la pena detenerse en ello: en la nueva sociedad gitana nacida de la educación, cada uno trabaja en lo que conoce mejor y prefiere, porque, en definitiva, 
cada uno trabaja para la comunidad. Nuestro único salario es el mantenimiento. Nadie conoce el valor del dinero, y toda la pequeña villa vive ahora muy feliz. Se esperan pronto grandes progresos, porque las inteligencias se desarrollan muy rápidamente. El futuro nos lo dirá ("chacun travaille pour la communauté. Notre seul salaire est la nourriture. Personne ns connaît la valeur de l'argent, et toute la petite ville vit maintenant très heureuse. On espère bientôt faire de grands progrès, car les cerveaux se développent très rapidement. L'avenir nous le dira", p.21).

No es extraño que los editores decidieran ilustrar este relato con dibujos infantiles ("dessins des enfants", se dice explícitamente), para que no quede duda en los posibles lectores de que este relato y su colofón de tintes fourieristas contienen fantasías, cosas propias de cuentos de hadas, solo concebibles desde la mente de los menores de edad que deben ser tutorizados por su propio bien. [imagen 4: dibujo de niño]

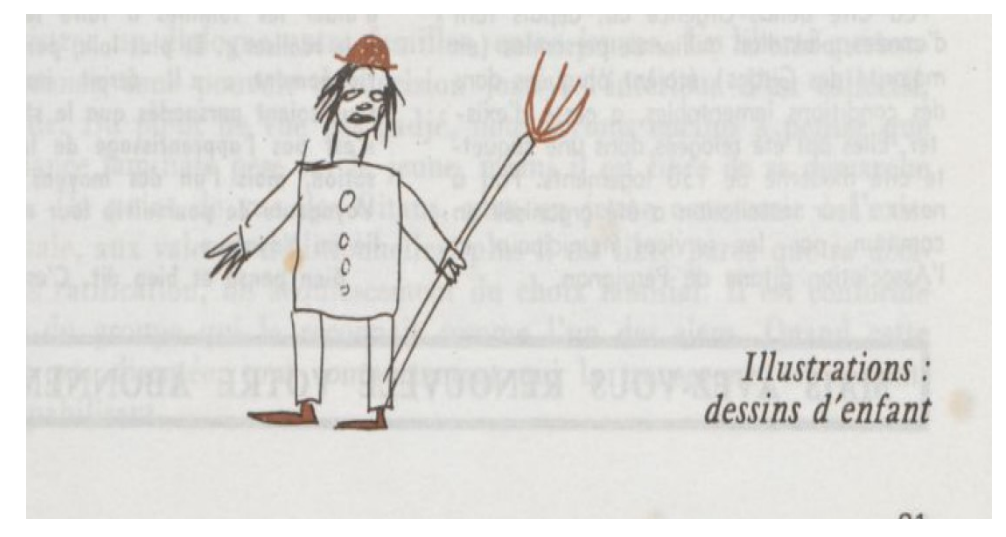

\section{BIBLIOGRAFÍA}

ABOUT, I. (2012): "Underclass Gypsies. An Historical Approach on Categorisation and Exclusion in France, in the Nineteenth and the Twentieth Centuries", en The Gypsy 'Menace'. Populism and the New Anti-Gypsy Politics, dirigido por Michael Stewart, London, Hurst, pp. 95-114. 
ACTON, T. A. [ed.] (1971): Current Changes among British Gypsies and their place in International Patterns of Development, Oxford, National Gypsy Education Council Conference Proceedings.

ACTON, T. A. (1974): Gypsy Politics and Social Change. The development of ethnic ideology and pressure politics among British Gypsies from Victorian reformism to Romany nationalism, London, Routledge.

ACTON, T. A. \& KLIMOVA, I. (2001): "The International Romani Union: An East European answer to West European questions? Shifts in the focus of World Romani organisations" en Between Past and Future: The Roma of Central and Eastern Europe, editado por W. Guy, Hatfield, University of Hertfordshire Press, pp.157-226.

CHARNON-DEUTSCH, L (2004): The Spanish Gypsy. The History of a European Obsession, The Pennsylvania State University Press.

FOGGS, S. L. (2003): "Assimilation and Persecution: An Overview of Attitudes toward Gypsies in France", en The Nazi Genocide of the Roma. Reassessment and Commemoration, editado por A. Weiss-Wendt, New York - Oxford, Berghahn, pp. 27-43.

GAUSSEN, D. (2017): "De Zanko, chef tribal à La Bible des Roms", en La Bible des Roms. La tradition Tsigane dévoilée par Zanko et recueillie par le Révérend Père Chatard, Marsella, Editions Gaussen - Association Tchatchipen, 2017, pp.11-23.

HEDDEBAUT, M (2018): Des Tsiganes ver Auchwitz. Le convoi $Z$ du 15 janvier 1944, s.l., Ed. Tiréias-Michel Reynaud.

KAPRALSKI, S. (2013): "The Aftermath of the Roma Genocide: From Implicit Memories to Commemoration", en The Nazi Genocide of the Roma. Reassessment and Commemoration, editado por A. Weiss-Wend, New York Oxford, Berghahn, pp. 229-251.

KENRICK, D. \& PUXON, G. (1972): The Destiny of Europe's Gypsies, London, Sussex Press.

KLIMOVA-ALEXANDER, I. (2005): "The Development and Institutionalization of Romani Representation and Administration. Part 2: Beginnings of modern institutionalization (Nineteenth Century-World War II), Nationalities Papers, Vol 33, N 2, pp. 155-210. 
KLIMOVA-ALEXANDER, I. (2006): "Development and Institutionalization of Romani Representation and Administration. Part 3a: From National Organizations to International Umbrellas (1945-1970)- Romani Mobilization at the National Level", Nationalities Papers, Vol 34, N 5, pp. 599-621.

LEVITAS, R. (2010): The Concept of Utopia, Berne, Peter Lang.

LIÉGEOIS, J.P. (1976): Mutation Tsigane, Brussels, Editions Complexe - Presses Universitaires de France.

LIÉGEOIS, J.P. (2009): Roms et Tsiganes, S.L., La Découverte, coll. Repères Sociologie.

LIÉGEOIS, J.P. (2017): “Zanko, de la tradition à l'engagement politique”, en La Bible des Roms. La tradition Tsigane dévoilée par Zanko et recueillie par le Révérend Père Chatard, Marsella, Editions Gaussen - Association Tchatchipen, pp. 7-10.

MANNHEIM, K. (2010): Ideology and Utopia, London, Routledge.

MARGALIT, G (2013): "The Justice System of the Federal Republic of Germany and the Nazi Persecution of the Gypsies", en The Nazi Genocide of the Roma. Reassessment and Commemoration, editado por Anton Weiss-Wendt, New York - Oxford, Berghahn, pp.181-204.

MILTON, S. (1998): "Persecuting the Survivors: The Continuity of 'AntiGypsyism' in Postwar Germany and Austria", en Sinti and Roma. Gypsies in German-Speaking Society and Literature, editado por Susan Tebbutt, New York, Berghahn Book, pp. 35-48.

PUXON, G. (2000), "The Romani Movement: Rebirth and the First World Romani Congress in Retrospect", en Scholarship and the Gypsy Struggle, editado por Thomas Acton, Hatfield, University of Hertfordshire Press, pp. 94-113.

SIERRA, M. (2018): "Historia gitana: enfrentarse a la maldición de George Borrow”, Ayer, 109 (2018), pp. 351-365.

SIERRA, M. (2019): "Creating Romanestan: A Place to be a Gypsy in Post-Nazi Europe”, European History Quarterly, V 49, Issue 2 (April 2019). https://doi.org/10.1177/0265691419836909

ZIMMERMANN, M. (2001): "The National Socialist 'Solution of the Gypsy Question': Central Decisions, Local Initiatives, and Their Interrelation", Holocaust and Genocide Studies, V5 N3, pp. 412-427. 
María Sierra es Catedrática de Historia Contemporánea en la Universidad de Sevilla. Ha dirigido cinco proyectos de investigación colectivos I+D dedicados a la historia comparada y trasnacional de la ciudadanía y la representación política, analizando la inclusión y la exclusión. Ha dedicado su atención al estudio de los fundamentos culturales de las actitudes políticas, interesándose por el género, las emociones y la cultura política. Entre sus publicaciones sobre estos temas, Enemies Within: Cultural Hierarchies and Liberal Political Models in the Hispanic World (2015). Actualmente dirige el proyecto de investigación "Historia de los gitanos: exclusión, estereotipos y ciudadanía" y el proyecto europeo "Beyon Stereotypes: Cultural Exchanges and the Romani Contribution to Euroepan Public Spaces". Resultados de esta líena de investigación son en artículos como "Creating Romanestan: A Place to be a 'Gypsy' in Post-Nazi Europe”, European History Quarterly (2019); "Uncivilized Emotions: Romantic Images and Marginalization of the Gitanos/Spanish Gypsies", Pakistan Journal of Historical Studies (2016) o "Historia gitana: enfrentarse a la maldición de George Borrow" (Ayer, 2018). Ha coordinado el dosier Gitanos: una historia negada en la revista Historia y Política (2018) y el monográfico Creando subalternos. Imágenes sobre el pueblo gitano en la revista Historia Social (2019). msierra@us.es 